\title{
La adaptación al uso turístico del patrimonio cultural. Una propuesta metodológica de evaluación
}

\author{
Ruben Arnandis-i-Agramunt \\ Rosa M. Yagüe Perales \\ María Dolores Pitarch Garrido \\ Universitat de València \\ ruben.arnandis@uv.es \\ rosa.m.yague@uv.es \\ maria.pitarch@uv.es
}

Recibido: agosto de 2018

Aceptado: mayo de 2019

Publicado: julio de 2020

\section{Resumen}

El patrimonio es una construcción sociocultural cuya función depende de los valores, intereses, tradiciones e identidades de cada sociedad y de cada momento, por lo que queda sujeta tanto a su valor intrínseco como a lo que representa. Cuando ese patrimonio despierta el interés en el turismo, se vislumbra una nueva función, pero, puesto que ningún patrimonio ha nacido con esa finalidad de ocio, su acondicionamiento resulta una tarea indiscutible. Esta investigación se centra en ese proceso de transformación para el uso turístico del patrimonio cultural inmueble, con el ánimo de identificar qué elementos son necesarios para que la actividad turística sea adecuada. La academia (vía Delphi) y los visitantes culturales (vía encuesta) han sido los grupos intervinientes mediante un cuestionario. Los resultados muestran consenso en ambos grupos con relación a los ítems propuestos para la metodología de evaluación, aunque también se evidencian algunas diferencias significativas que abren las puertas a futuras vías de investigación.

Palabras clave: patrimonio cultural; uso turístico; evaluación; visitantes; academia 
Resum. L'adaptació a l'ús turístic del patrimoni cultural. Una proposta metodològica d'avaluació

El patrimoni és una construcció sociocultural i la seva funció depèn dels valors, interessos, tradicions i identitats de cada societat i de cada moment, de manera que queda subjecta tant al seu valor intrínsec com a allò que representa. Quan aquest patrimoni desperta l'interès en el turisme, apareix una nova funció, però, com que cap patrimoni ha nascut amb la finalitat d'oci, el seu condicionament resulta una tasca indiscutible. Aquesta investigació se centra en aquest procés de transformació per a l'ús turístic del patrimoni cultural immoble, amb l'ànim d'identificar quins elements són necessaris perquè l'activitat turística sigui adequada. L'acadèmia (via Delphi) i els visitants culturals (via enquesta) han estat els grups implicats mitjançant la realització d'un qüestionari. Els resultats mostren consens en els dos grups sobre la majoria d'ítems proposats per a la metodologia d'avaluació, però entre ells també s'evidencien diferències significatives que obren la porta a futures vies d'investigació.

Paraules clau: patrimoni cultural; ús turístic; avaluació; visitants; acadèmia

Résumé. L'adaptation du patrimoine culturel à l'emploi touristique. Une proposition méthodologique d'évaluation

Le patrimoine constitue une construction socioculturelle dépendante des valeurs, des intérêts, des traditions et des identités de chaque société et de chaque situation. Cependant, elle est subordonnée à sa propre valeur mais aussi à ce qu'il représente. Quand ce patrimoine réveille de l'intérêt dans le domaine du tourisme, une nouvelle fonction apparaît mais étant donné qu'aucun patrimoine n'a été conçu dans un objectif de loisirs, l'aménagement de ce dernier devient dès lors un travail nécessaire. Ce travail se centre donc sur ce processus de transformation du patrimoine culturel immobilier dans le cadre de son utilisation touristique, dans l'idée d'identifier quels sont les éléments nécessaires pour que l'activité touristique soit adéquate. L'académie (Delphi) et les visiteurs culturels (enquête) ont été soumis à un questionnaire. Les résultats montrent une coïncidence dans les deux groupes pour la plupart des items proposés pour la méthodologie d'évaluation, même si l'on peut entrevoir certaines différences significatives qui ouvrent la porte à de futures lignes de recherche.

Mots-clés: patrimoine culturel; emploi touristique; évaluation; visiteurs; académie

Abstract. Adaptation of cultural heritage for tourism use: A methodological proposal for evaluation

Heritage is regarded as a socio-cultural construct whose function depends on the values, interests, traditions and identities of each society at each moment in time. In this sense, heritage is understood not only in terms of its intrinsic value, but also its meaning. Given that heritage was not originally conceived of for purposes of leisure, when heritage attracts tourism it assumes a new function that must be accommodated in a suitable manner. This investigation focuses on the process of creating immovable cultural heritage for tourism use in order to identify the necessary transformations to successfully fulfill visitors' expectations. To evaluate this issue, a questionnaire was administered to academics (via Delphi) and visitors (via a survey). In the majority of items, the results showed a consensus between both groups regarding the assessment methodology, although significant differences were also found, thus leaving the door open to future research.

Keywords: cultural heritage; tourism use; evaluation; visitors; academy 


\section{Sumario}
1. Introducción
4. Resultados
2. El patrimonio cultural como materia
5. Conclusiones
prima para el turismo
Referencias bibliográficas

\section{Metodología}

\section{Introducción}

En los últimos años, han aumentado desde la geografía estudios que consideran que el patrimonio cultural es un elemento clave en la comprensión de los procesos territoriales relacionados con actividades ligadas al turismo y/o al ocio, por ser el patrimonio un contenedor de valor para ellas. Desde una mirada amplia y sobre un cierto consenso entre quienes lo estudian, Hernàndez i Martí et al. (2005) definen el patrimonio a partir de un conjunto de rasgos: a) es una "construcción sociocultural» (no se trata de algo natural, ni es dado ni neutro); b) tiene "carácter simbólico" (en relación con el valor del patrimonio como conjunto de valores, demandas y moralidades contemporáneas que le dan sentido) (Graham et al., 2000); c) se conforma por una multitud de imágenes, según contextos culturales, que responderán a un «mapa de atribuciones y valores» muy complejo.

En cambio, Bonfill (1993), Ballart y Juan i Tresserras (2001), Ariño (2002), Fernández (2003), Almirón et al. (2006), Velasco (2009) y Valle y Soledad (2015) prefieren definir el patrimonio como el acervo de una sociedad o, en un sentido más amplio, como el conjunto de bienes (naturales, culturales, materiales e inmateriales) acumulados paulatinamente por tradición o herencia que son comunes a un conjunto de individuos que constituyen esa sociedad (Conti y Cravero, 2010; Marcos, 2004; UNESCO, 2014).

Así pues, el patrimonio no es más que «el resultado de un proceso de selección influenciado por valores, ideas e intereses contemporáneos, llevado a cabo por actores sociales (políticos, científicos, expertos, sociedad civil)» (Prats, 1998: 66). Y es cuando el patrimonio tiene la posibilidad de alcanzar una finalidad de consumo, utilización directa u obtención de beneficios por su puesta en circulación y venta, cuando "ese valor material convierte al patrimonio en recurso económico que queda a expensas de la oferta y la demanda» (Moncusí, 2005: 108).

Bajo esa puesta en circulación y venta del patrimonio cultural, este artículo toma como referencia las propuestas teóricas de Velasco (2009) y Mateos (2012), entre otros, y asume que ningún patrimonio cultural inmueble (en adelante, PCI) ha nacido con una finalidad turística, por lo que dicho uso solo será posible a partir de una serie de adaptaciones (físicas e intangibles) con el ánimo de preservar su integridad, gestionar adecuadamente su uso y garantizar el disfrute de quien lo visita. Con estas premisas, esta investigación tiene por objeto proponer un marco para evaluar la adaptación al uso turístico del PCI a partir de la valoración de quienes lo viven (visitantes) y lo estudian (academia). 


\section{El patrimonio cultural como materia prima para el turismo}

\subsection{Algunas aclaraciones en torno al concepto de recurso turistico}

Los estudios relacionados con la materia prima del turismo han estado faltos de una definición clara y rigurosa capaz de establecer como punto de partida en qué consiste (Ávila, 2008; Leiper, 1990; Swarbrooke, 2002; Walsh-Heron, 1990). Todavía hoy parece no existir un acuerdo consensuado sobre qué constituye un recurso turístico (Leask y Fyall, 2006; Richardson, 1996; Swarbrooke, 2002; Weaver y Lawton, 2007; Weidenfeld y Leask, 2013), debido a la amplia variedad de perspectivas existentes (desde la óptica del visitante, desde su gestión, desde la investigación, desde su marco normativo), de términos universalmente utilizados (atractivo, características, sitio, lugar, espacio...), del cambio constante y la diversidad de los intereses de los visitantes (descanso, acción, prestigio, solidaridad, curiosidad...) y de la variabilidad de recursos turísticos (balnearios, parques naturales, centros urbanos, parques temáticos...) (Lew, 1987; Pearce, 1991; 1998; Stevens, 1991). Quizás esta es la razón por la que existen múltiples aportaciones (Arnandis-i-Agramunt, 2017).

Partiendo de los trabajos previos de la UIOOT (1971), se entiende por recurso turístico "aquel elemento territorial que, al provocar un interés turístico, puede ser utilizado para la formación de la oferta turística» (Unión Internacional de Organismos Oficiales de Turismo, 1971: 14). Convertida ocho años después en la Organización Mundial del Turismo (OMT), esta puntualiza que aquel bien «requiere [además] de la intermediación de la actividad del ser humano y de los medios con los que cuenta", para hacer posible la actividad turística y satisfacer las necesidades de la demanda (World Tourism Organization, 1979: 3)

Así pues, es la OMT, en el diseño de su Teoría de la Renovación del Patrimonio Turístico, la que introduce en el concepto de recurso turístico la necesidad de que haya, además de atracción, una transformación humana para su adaptación a la actividad turística, y esto es la diferencia entre un elemento neutro y un recurso turístico.

Para Gunn (1997), Anton et al. (2007) y Conti y Cravero (2010) no existe otro modo de entenderlo, pues todo recurso requiere de un acondicionamiento físico, temporal y económico para dotarlo de mayor atractivo que permita cautivar visitantes, pero también para que sea gestionado convenientemente con el objeto de que pueda sobrevivir a su función original, en caso de que siga teniéndola. Así pues, hoy en día todo recurso turístico se adapta de un modo u otro a ese uso. Especialmente, los que no han nacido con esa finalidad, lo que hace imposible admitir que un recurso sea turístico simplemente por el hecho de otorgarle esa condición de atracción.

\subsection{El patrimonio cultural como recurso turístico: el nosotros de los otros}

Almirón et al. (2006) señalan que la conversión del patrimonio en recurso turístico merece ser analizada con detenimiento. Bien es cierto que el valor 
universal, el carácter compartido y consensuado, el hecho de estar más allá de cuestionamientos sobre su valoración, la idea de ser la vía de acceso a un conjunto de significados que van más allá del lugar u objeto de que se trate, etcétera, parecen ser argumentos suficientes para convertir al patrimonio en un recurso turístico de primer nivel.

Esto lleva a cuestionarse que tal vez hay un determinado tipo de patrimonio más susceptible de ser reconocido como turístico o que existen ciertos rasgos del conjunto del patrimonio que son valorizados por el turismo frente a otros. Debe reconocerse, pues, que considerar un patrimonio como recurso turístico implica, además de la primera selección del elemento como patrimonio, una segunda elección en la que se desechará aquel patrimonio que no sea de interés. De este modo, el turismo resignifica el patrimonio a partir de procesos sociales de construcción del atractivo, lo que Prats (1997: 42) denomina el «nosotros de los otros", por esa imagen que se construye de nosotros mismos para aquellos que nos visitan. Como explican Hernàndez i Martí et al. (2005), el patrimonio conforma en gran parte nuestra imagen cultural autorreflejada, mientras que el turismo la proyecta convenientemente retocada, tamizada y filtrada hacia los territorios del exterior.

El interés por desarrollar el turismo en un determinado lugar puede activar y orientar el proceso de descubrimiento de potenciales patrimonios para su directa transformación en recurso turístico. Pero ¿por qué utilizar el patrimonio como elemento turístico? Sencillamente porque, como indican Silva y Fernández (2008), los elementos patrimoniales ya están cargados de símbolos y de reconocimiento, más si son reconocidos institucionalmente, y porque acrecientan el valor añadido de tales bienes por cuanto suelen asociarse a una garantía de calidad y autenticidad (Lima et al., 2012). Es lo que Bourdieu (1998) señala sobre el patrimonio como recurso turístico: son los discursos y las prácticas a aquel asignadas lo que carga a este de una positividad superlativa, $\mathrm{y}$ esta positividad es la que parece ser el núcleo de su atractivo, y no sus cualidades intrínsecas las que justifican su transformación en producto de consumo.

\subsection{La adaptación del patrimonio cultural al uso turístico}

Adecuar los recursos patrimoniales para el turismo pasa por establecer una relación estrecha entre ambos (turismo y patrimonio), capaces de representar una oportunidad de proporcionar diferentes lecturas y alternativas de los recursos, a la vez que poner en marcha un instrumento de valoración de la función social y económica de dicho patrimonio (Monteserin, 2008). Además, puesto que la valoración del patrimonio es en sí misma un instrumento de territorialización, en tanto en cuanto la construcción de este solo es posible en una contextualización original (Ballart y Juan i Tresserras, 2001), la estrategia frente a otros destinos se asienta justamente en esa identidad, más si es singular y única, por su capacidad de generar esa diferenciación competitiva siempre tan anhelada.

El objetivo de esta adaptación al uso turístico del patrimonio debería ser, pues, una nueva fórmula de práctica cultural (Cortes, 2002), sin dejar de lado 
que tales valores patrimoniales en muchas ocasiones son un modo evidente de generar beneficio (Toselli, 2006). No obstante, el uso turístico del patrimonio debe diseñarse siempre bajo unos principios éticos, regulando y contextualizando las actividades posibles a las condiciones del mantenimiento y fomento del patrimonio, garantizando que no habrá impactos nocivos como el sobredimensionamiento de su capacidad de acogida, la banalización de su uso (Marchena y Repiso, 1999), la aculturación de la sociedad y la gentrificación (Conti y Cravero, 2010) o la degradación ambiental donde esté inserto.

Por todo ello, debe evitarse en todo momento (Pinassi, 2012):

a) La musealización interpretada del patrimonio como si de un proceso de embalsamamiento se tratase.

b) Racionalizar la organización de la producción y el consumo de cualquier producto turístico atendiendo a los elementos que lo conforman para dotarlo de excepcionalidad (Middleton, 1994).

c) Maximizar la eficacia de los procesos productivos y de consumo (Ritzer, 1996).

d) Las iniciativas que solo conllevan declaraciones de intención y promoción de imágenes sin contenido apto para su uso turístico.

e) La clonación de iniciativas turísticas asentadas en el mismo tipo de patrimonio.

f) La homogeneización de servicios y equipamientos sobre elementos culturalmente distintos.

En principio, todos pueden parecer procedimientos precisos para establecer un desarrollo y un funcionamiento de recursos turísticos. Partiendo de la idea central de que el patrimonio es un elemento de la memoria colectiva de los lugares y de las sociedades, debe ser preservado más allá de su uso recreativo, por lo que debería existir un compromiso ético para que «no se convierta únicamente en una atracción» (Anton, 2000: 35).

En esta línea, Velasco (2009) expone tres aspectos clave en la conversión del patrimonio en recurso turístico: la planificación, la evaluación y la conceptualización del bien. Esta última es la que se compone en esencia de dos postulados: la política de conservación y las propuestas de uso. Sobre el primero de ellos, la política de conservación, la autora sigue la línea argumental de otros trabajos, citados anteriormente y cuyo máximo exponente es la Cartade Venecia (ICOMOS, 1966), en los que se expone que la conservación del bien debe ser el objetivo básico de cualquier política patrimonial. También en la gestión turística del patrimonio cultural se deja constancia de esta finalidad (ICOMOS y UNWTO, 1993). Por ello, aclara que resulta vital una política de conservación como base para la posterior propuesta de gestión. De este modo, la "gestión turística del patrimonio cultural ya contemplará necesariamente principios esenciales» (Velasco, 2009: 249): cómo proteger al recurso de los daños causados por el uso turístico, cómo establecer estrategias que permitan la conservación de los elementos materiales que pueden ser dañados y cómo 
Tabla 1. Materialización de la conversión del patrimonio cultural en recurso turístico

\begin{tabular}{ll}
\hline Acción & Material \\
\hline Diseño de soportes para públicos diferentes & $\begin{array}{l}\text { Acciones pedagógicas, programas escolares, } \\
\text { visitas para la tercera edad... }\end{array}$ \\
\hline Diseño de soportes para turistas & $\begin{array}{l}\text { Guías, planos, presentaciones narradas, } \\
\text { traducciones... }\end{array}$ \\
\hline $\begin{array}{l}\text { Diseño de soportes para visitantes con necesi- } \\
\text { dades especiales }\end{array}$ & $\begin{array}{l}\text { En función del tipo de discapacidad: intelectual, } \\
\text { motora, auditiva y visual }\end{array}$ \\
\hline Plan de señalización & $\begin{array}{l}\text { Entrada, salida, aseos, emergencia, extintores... } \\
\text { Incorporación del bien en rutas culturales }\end{array}$ \\
\hline Servicios para visitantes & $\begin{array}{l}\text { Distribución, promociones, tarjetas de fideliza- } \\
\text { ción... }\end{array}$ \\
\hline Consideraciones de seguridad & $\begin{array}{l}\text { Zona de descanso, tienda de recuerdos, } \\
\text { servicio médico, aseos... }\end{array}$ \\
\hline
\end{tabular}

Fuente: elaboración propia a partir de Velasco (2009: 250).

conservar el carácter simbólico y cultural de aquello que pretende convertirse en producto turístico.

Respecto al segundo postulado, las propuestas de uso (certificada ya la conservación), se requiere necesariamente conocer el perfil de los posibles usuarios del patrimonio para garantizar los diferentes usos y, con ello, la pervivencia del bien, por lo que un estudio previo resulta del todo adecuado para asegurar una correcta conexión entre lo que el visitante espera y lo que el bien puede ofrecerle.

Identificados los potenciales usuarios, las propuestas de uso devendrán tras un proceso de análisis, reflexión y diseño, que impulsarán aquellos aspectos del bien que puedan ser susceptibles de convertirse en interés para el visitante. En una segunda fase, se abordará ya la materialización de dicha propuesta, es decir, la producción de los elementos que conformarán esa conversión del patrimonio cultural en recurso turístico (tabla 1).

La propuesta de Mateos (2012), denominada activación patrimonial (figura 1), se centra en particular en la dotación de servicios (de apoyo y de mediación) a un patrimonio para que este sea capaz de acoger las condiciones necesarias (físicas, simbólicas, emocionales, lúdicas...), «con el objetivo de satisfacer al visitante» (Mateos, 2012: 4). Como define el autor, es un proceso por el cual el recurso patrimonial pasa de lo meramente material a lo inmaterial (producto patrimonial). Estos servicios, que dotan al patrimonio de capacidad para su uso y consumo, son divididos en dos grupos distintos, aunque no existen jerarquías entre ellos:

1. Servicios de apoyo: son los que facilitan el desarrollo de un ambiente adecuado para asegurar la experiencia cultural y aseguran una visita confortable. Serían, 
entre otros, la señalética de orientación, la señalética de información, la recepción, los aseos, la tienda, espacios de descanso, servicios de cafetería...

2. Servicios de mediación: son lo que conectan al visitante con el bien patrimonial a nivel sensorial, emocional y cognitivo, y conforman el núcleo del producto patrimonial para dale sentido. Serían fundamentalmente los audiovisuales, las maquetas, las rutas guiadas, las audioguías, las recreaciones escenográficas...

En este caso, puede observarse que el autor concibe el núcleo del recurso como el elemento clave, sobre el cual debe recaer el significado y la dotación de contenidos. De este modo, se postula junto a los modelos teóricos de Gunn (1972), MacCannell (1976) y Leiper (1990) sobre la adaptación al uso turístico de los recursos (Arnandis-i-Agramunt, 2018).

Figura 1. Importancia de la activación patrimonial

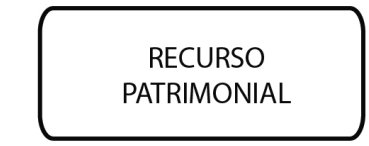

No se explota su potencial comunicativo para el gran público

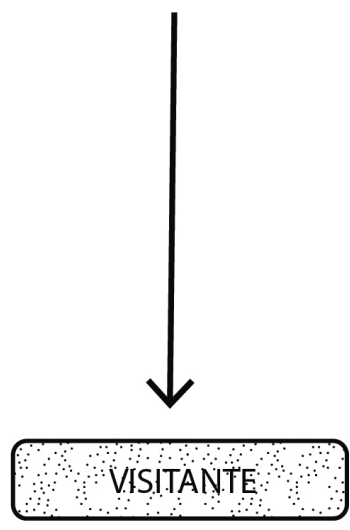

El gran público, al desconocer el código comunicativo del recurso patrimonial, es incapaz de comunicarse con él.

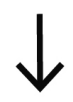

experiencia frustrante

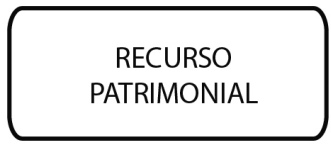

Se decide explotar su potencial comunicativo para el gran público

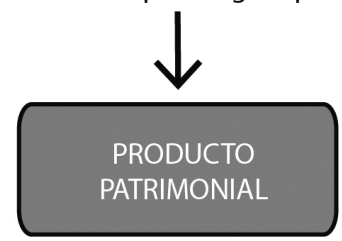

Se crean los servicios y elementos de mediación que decodifican la información

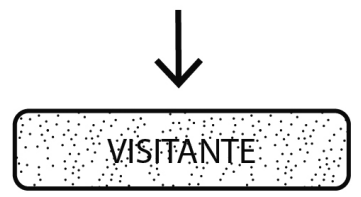

Se le descubre al gran público el código comunicativo del recurso patrimonial, estableciéndose una conexión con él.

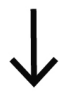

experiencia enriquecedora

Fuente: elaboración propia a partir de Mateos (2012: 5). 
Presentada la revisión de la literatura en esta materia, se pasa a continuación a exponer el marco metodológico sobre el que estructurar el objeto de esta investigación.

\section{Metodología}

A raíz de las aportaciones teóricas citadas en el apartado anterior, y especialmente las propuestas por ICOMOS y UNWTO (1993), Gunn (1997), OMT (1999), Velasco (2009) y Mateos (2012), centradas en torno a las adecuaciones necesarias (físicas e intangibles) del patrimonio cultural para que pueda desempeñar un uso turístico, se determinó el constructo Elementos de adecuación del patrimonio cultural inmueble al uso turistico (tabla 2).

Tabla 2. Elementos de adecuación del patrimonio cultural inmueble al uso turístico

\begin{tabular}{|c|c|c|c|}
\hline Dimensión & & Indicador & N..$^{\circ}$ ítems que incluye \\
\hline \multirow[t]{3}{*}{ Servicios de apoyo } & D1 & Política de acceso & 6 \\
\hline & $\mathrm{D} 2$ & Servicios generales & 9 \\
\hline & D3 & Señalética & 7 \\
\hline Servicios de mediación & D4 & Interpretación & 8 \\
\hline
\end{tabular}

Fuente: elaboración propia a partir de Mateos (2012).

De esta literatura se extrajeron un total de 30 ítems, distribuidos en dos dimensiones y cuatro indicadores, que a través de un cuestionario serían puntuados por ambas muestras con una escala de valoración Likert de cinco puntos.

Primeramente, se realizó una investigación exploratoria de carácter cualitativo a la academia a través de un Delphi ${ }^{1}$. Esta técnica resulta precisa en contextos de información imperfecta por su facilidad para combinar el conocimiento y la experiencia en diversos campos (Donohoe y Needham,

1. El Delphi se considera un método acertado frente a otras alternativas o técnicas de investigación social, según Turoff (1971), cuando se requiere que los individuos participantes contribuyan en la investigación de un problema complejo del que no existen antecedentes. Habibi et al. (2014) coinciden con este autor al señalar que «el Delphi puede ser utilizado en las investigaciones cualitativas de carácter exploratorio que, como base del estudio, deseen identificar la naturaleza y los fundamentos elementales de un fenómeno" (Habibi et al., 2014: 10). Por otro lado, Flores (2010), Johnson y King (1988), Kaynak y Macaulay (1984), Pulido (2007), Solsona (2010) y Tsaur et al. (2006) defienden que el conocimiento grupal resulta mejor que el de un solo experto en aquellas áreas donde la información es escasa o no se encuentra disponible, y es demostrado de forma experimental por Kaplan et al. (1950). Donohoe y Needham (2009) o Konu (2015) afirman que a día de hoy este método es considerado válido, ya que el discurso actual en torno a él ha cambiado por su aplicación metodológica y refinamiento. Landeta et al. (2011) y Rowe y Wright (2011) lo consideran acertado, siempre y cuando forme parte de un proceso metodológico más amplio y se combine con otras técnicas cuantitativas y cualitativas, como sucede en este estudio. 
Tabla 3. Estructura del Delphi y de la encuesta para esta investigación

\begin{tabular}{|c|c|c|}
\hline \multirow[b]{2}{*}{ Fase } & Encuesta & Delphi \\
\hline & \multicolumn{2}{|c|}{ Descripción } \\
\hline $\begin{array}{l}\text { Planteamiento } \\
\text { del objeto de } \\
\text { aplicación }\end{array}$ & \multicolumn{2}{|c|}{$\begin{array}{l}\text { Comparación de las valoraciones de la academia y los visitantes culturales } \\
\text { sobre los elementos que identifican la adaptación al uso turístico de un PCl } \\
\text { no nacido con una finalidad turística. }\end{array}$} \\
\hline $\begin{array}{l}\text { Preparación de } \\
\text { las cuestiones } \\
\text { a investigar }\end{array}$ & \multicolumn{2}{|c|}{$\begin{array}{l}\text { A partir de los hallazgos encontrados en la literatura revisada para el marco } \\
\text { teórico, se definen dos dimensiones (Mateos, 2012), cuatro indicadores y } \\
30 \text { ítems. }\end{array}$} \\
\hline Cuestionario & \multicolumn{2}{|c|}{$\begin{array}{l}\text { Diseñado en Google Forms. Las personas participantes expresaron su } \\
\text { grado de acuerdo, en una escala Likert de } 1 \text { a } 5 \text {, sobre cada ítem. Se aplicó } \\
\text { previamente un pretest y se determinó el coeficiente de Alfa de Cronbach } \\
\text { para comprobar la fiabilidad interna del constructo. }\end{array}$} \\
\hline $\begin{array}{l}\text { Selección de la } \\
\text { muestra y criterios } \\
\text { de contacto }\end{array}$ & $\begin{array}{l}\text { A partir de las indicaciones realiza- } \\
\text { das por ATLAS (2007) para el perfil } \\
\text { del visitante cultural. Considerando } \\
\text { un error muestral del 5\% para un } \\
95 \% \text { de confianza, se realizaron } 389 \\
\text { encuestas. Personas que accedían } \\
\text { a la Lonja pero todavía no habían } \\
\text { pagado el tique, hombre y mujer } \\
\text { consecutivamente, de fuera de } \\
\text { Valencia ciudad, que previamente } \\
\text { seleccionaban de un listado que su } \\
\text { viaje a Valencia estaba relacionado } \\
\text { con un interés cultural y que habían } \\
\text { visitado en otros viajes anteriores } \\
\text { algún patrimonio cultural inmueble } \\
\text { que requería acceso a su interior. }\end{array}$ & $\begin{array}{l}\text { A partir de la creación de un algo- } \\
\text { ritmo que calcula el valor de cada } \\
\text { persona experta en base al } n .^{\circ} \text { de } \\
\text { publicaciones sobre la temática y } \\
\text { otras afines objeto de esta investi- } \\
\text { gación. Inicialmente, se envío a los } \\
\text { primeros } 50 \text { panelistas una invitación } \\
\text { junto con el enlace al formulario. Al } \\
\text { día siguiente, se les contactó telefó- } \\
\text { nicamente para presentarse y expli- } \\
\text { car en detalle el objeto del estudio. } \\
\text { Participaron finalmente } 25 \text { persona } \\
\text { tras la segunda ronda. }\end{array}$ \\
\hline $\begin{array}{l}\text { Lugar de recogida } \\
\text { de datos }\end{array}$ & Lonja de Valencia & Online \\
\hline $\begin{array}{l}\text { Fecha de recogida } \\
\text { de datos }\end{array}$ & $\begin{array}{l}\text { Del } 03.08 .2016 \text { al } 28.08 .2016 \text {, de } \\
\text { lunes a sábado, en horario de } 10 \\
\text { a } 13 \text { horas y de } 16 \text { a } 19 \text { horas. Se } \\
\text { excluyó el domingo por ser un día } \\
\text { de entrada libre. }\end{array}$ & $\begin{array}{l}\text { Primera ronda: del } 26.04 .2016 \text { al } \\
\text { 17.05.2016. } \\
\text { Segunda ronda: del } 01.06 .2016 \text { al } \\
\text { 26.06.2016. Las personas partici- } \\
\text { pantes recibieron un documento con } \\
\text { el valor de la mediana del grupo en } \\
\text { cada ítem, valor del rango intercuar- } \\
\text { tílico, \% de frecuencia de la moda en } \\
\text { cada ítem y sus valoraciones fuera } \\
\text { de mediana. }\end{array}$ \\
\hline
\end{tabular}

Fuente: elaboración propia

2009; Konu, 2015), y es en esta vertiente prospectiva donde reside su mayor valor: obtener información con un enfoque científico (Linstone y Turoff, 2002).

Dentro del ámbito turístico, pueden observarse de manera concreta dos tipos de finalidades en la aplicación del Delphi (Donohoe y Needham, 2009; Konu, 2015): en primer lugar, en aquellas temáticas relacionadas con el pronóstico e identificación/priorización y, en segundo lugar, en las vinculadas 
al desarrollo de marcos teóricos (como se desea en esta investigación), con la focalización de los esfuerzos hacia el desarrollo/refinamiento de teorías o modelos conceptuales y sus componentes.

Para implementar esta técnica de investigación, se ha seguido, fundamentalmente, la estructura y las recomendaciones propuestas por Landeta (2002; 2006), se han considerado otros trabajos, como los de Coll-Serrano et al. (2013), Pulido (2007; 2009), Solsona (2010), Tsaur et al. (2006), y se han introducido algunos matices en función de las particularidades propias de este trabajo (tabla 3), sin olvidar que no existen unas pautas universalmente aceptadas para el uso del Delphi ni un método estandarizado para su administración (Ballantyne et al. 2016).

Con todas estas premisas y para seleccionar al equipo de personas expertas en la materia, se consideró adecuado recurrir inicialmente al portal bibliográfico DIALNET. A partir de las palabras clave más afines a la temática de esta investigación (adaptación uso turistico, puesta valor turístico, recursos turísticos, atractivos turísticos) y el filtrado por relevancia, artículos en revistas, CIRC2012, CARHUS+2014, Latindex, en español, se obtuvo un listado de personas cuya investigación quedaba vinculada a estas keywords. El total inicial de posibles candidaturas ascendió a 121, si bien algunas se repetían en más de un listado. Posteriormente, fueron analizándose los perfiles de cada persona (para asegurarse que todas estuvieran vinculadas a instituciones académicas y que sus publicaciones no fueran traducciones al español) y su producción (A, artículos; C, colaboraciones; L, libros, y Co, coordinaciones). El objeto era cuantificar su experiencia a partir de un indicador que pudiera reflejar la relevancia relativa de esa persona con el tema de investigación. Para el cálculo de ese valor individual, se determinó la función siguiente (gráfico 1).

Gráfico 1. Cálculo del índice de relevancia de cada autor/a

$$
\mathbb{R}=\left(\frac{\Sigma X T i}{\Sigma X T n}+\frac{\Sigma X R T i}{\Sigma X R T n}\right)-\left(\frac{\Sigma X T i-\Sigma X i n}{\Sigma X T n-\Sigma X n}\right)
$$

siendo,

¿XTi Total de $\mathrm{A} / \mathrm{C} / \mathrm{L} / \mathrm{Co}$ en turismo del autor/a

¿XTn Total de $\mathrm{A} / \mathrm{C} / \mathrm{L} / \mathrm{Co}$ en turismo de la muestra

¿XRTi Total de A/C/L/Co específicos en "palabra clave" del autor/a

¿XRTn Total de $\mathrm{A} / \mathrm{C} / \mathrm{L} / \mathrm{Co}$ específicos en "palabra clave" de la muestra

$\Sigma X i n \quad T o t a l$ de $\mathrm{A} / \mathrm{C} / \mathrm{L} / \mathrm{Co}$ publicados por el autor/a

$\Sigma \mathrm{Xn} \quad$ Total de $\mathrm{A} / \mathrm{C} / \mathrm{L} / \mathrm{Co}$ publicados de la muestra

Fuente: elaboración propia. 
Tabla 4. Evolución de la muestra para el Delphi

\begin{tabular}{lccccc}
\hline \multicolumn{1}{c}{ Situación } & Teléfono & Mail & RRSS & Total & \% Abandono s/total \\
\hline No pudo contactarse & 3 & - & 1 & 4 & - \\
Pudo contactarse & 18 & 26 & 2 & 46 & - \\
Aceptan participar & 18 & 15 & 2 & 35 & - \\
1. ${ }^{\text {a }}$ ronda & 17 & 11 & 2 & 30 & $14,29 \%$ \\
2. ${ }^{\text {randa }}$ & 13 & 10 & 2 & 25 & $16,67 \%$ \\
\hline
\end{tabular}

Fuente: elaboración propia.

Esta función, afectada por cuatro variables, obtiene el valor de cada posible panelista condicionado según el número de publicaciones totales del autor/a, de ellas las que corresponden a turismo, de estas las que corresponden a las palabras clave y, además, condicionado al total de la muestra. De este modo, una persona con muchas publicaciones pero pocas de turismo y menos en las temáticas buscadas obtiene un menor valor que aquella que, con un número menor de publicaciones, tiene una mayor concentración relativa de investigaciones en las materias de referencia. A aquellas personas que aparecían en más de una lista (según las keywords introducidas) se les sumó el valor conjunto. Finalmente, el número de posibles panelistas se quedó en 108. De este total, solo 32 obtuvieron un valor positivo en el indicador, es decir, que su investigación en materia turística vinculada con la temática del estudio era mayoritaria sobre el total de su investigación. Se tomaron como referencia las primeras 50 personas (tabla 4), de acuerdo con las recomendaciones de Dalkey et al. (1969) y Lee y King (2008) sobre el umbral mínimo de 20 panelistas para minimizar el error y aumentar la fiabilidad de los resultados, conscientes de la posible pérdida de panelistas durante las rondas.

Las disciplinas integradas en el Delphi, y que finalizaron las rondas, fueron Geografía (20 participantes), Antropología (1 participante), Historia del Arte (1 participante), Sociología (1 participante), Organización de Empresas (1 participante), Turismo (1 participante). La gran mayoría de panelistas de Geografía viene explicada porque, tradicionalmente, esta disciplina acapara las investigaciones vinculadas con los recursos turísticos, en concreto, el área de conocimiento de análisis geográfico regional.

En segundo lugar, de carácter cuantitativo, tomando en consideración lo que señala Velasco (2009) sobre la importancia de integrar las valoraciones de los visitantes en cualquier propuesta de conversión del patrimonio cultural en recurso turístico, se llevó a cabo una encuesta a visitantes culturales ${ }^{2}$. Seg-

2. Aunque algunos autores como Calle (2002) exponen que el nivel de estudios puede considerarse como una variable diferenciadora de quienes practican el turismo cultural, él mismo afirma que no existe ninguna tipología de turista que pueda asentarse en un único criterio por ser excesivamente simplista. Solo las segmentaciones multicriterio reflejan de forma más adecuada la complejidad del fenómeno turístico y sus innumerables perfiles de visitante (2002). Por esta razón, en el cuestionario aplicado a visitantes, se les preguntó inicialmente que se ubicaran en uno de los cuatro supuestos que mejor definían su perfil 
Tabla 5. Límites para el análisis de los resultados

\begin{tabular}{llllll}
\hline & \multicolumn{2}{c}{ Consenso } & & \multicolumn{2}{c}{ Disenso } \\
\cline { 1 - 2 } Acuerdo & Desacuerdo & Indeciso/Indiferente & & Discordante & Indeterminado \\
\hline Mediana $\geq 4$ & Mediana $\leq 2$ & Mediana $=3$ & & Región $[1,2] \geqq 33 \%$ & Ninguna de \\
Región $[4,5] \geq 66 \%$ & Región $[1,2] \leq 66 \%$ & Región $[3] \geq 66 \%$ & & Región $[4,5] \geqq 33 \%$ & las anteriores \\
$\mathrm{Rl} \leq 1$ & $\mathrm{Rl} \leq 1$ & $\mathrm{Rl} \leq 1$ & & \\
\hline
\end{tabular}

Fuente: elaboración propia.

mentada la muestra según las premisas identificadas por el proyecto ALTAS (Association for Tourism and Leisure Education and Research): 53\% hombres, 47\% mujeres, 30\% jóvenes entre 20 y 29 años, 70\% estudios universitarios, con los datos tomados en la Lonja de Valencia. Se optó por este espacio por ser el primer referente cultural de carácter turístico de la ciudad (Fundación Turismo Valencia), ser el único Patrimonio de la Humanidad de carácter inmueble presente, por no tener asociado ningún carácter religioso, por encontrarse en un espacio de fácil acceso y, fundamentalmente, porque, a diferencia de los tres primeros recursos turísticos de la ciudad (Museo Príncipe Felipe, L'Oceanogràfic, Bioparc), la Lonja no nació inicialmente con una finalidad turística, aspecto que no cumplen los anteriores recursos.

En relación con el análisis de los datos obtenidos en ambas muestras, se estimó conveniente reordenar la escala Likert en calificadores lingüísticos (Pedro-Botet et al., 2016; Plaza et al., 2012). De este modo, las respuestas ofrecidas se reagrupan y concentran en tres regiones según la escala de medida utilizada: $[1,2]$ = en desacuerdo; [3] = indeciso/indiferente; $[4,5]=$ de acuerdo. Posteriormente, se analizaron los datos a partir del porcentaje de respuestas concentradas en cada región, de la mediana y del rango intercuartílico. La justificación del uso de la mediana se asienta en que, cuando las escalas que se utilizan son de tipo ordinal, usar la media y la desviación típica es "un procedimiento incorrecto, estrictamente hablando» (Argyrous, 2011: 185).

La mediana y el rango intercuartílico se presentan como medidas más robustas, pues muestran la dispersión en valores enteros. Y puesto que para este caso se utiliza una escala Likert de pocos valores, puede establecerse la unidad como valor máximo del RIC, ya que aceptar valores superiores sería asumir un grado elevado de error (Murphy et al., 1998). Así pues, un ítem se consideró consensuado cuando los tres indicadores estaban dentro de los límites establecidos en esta investigación (tabla 5). Además, se estimó conveniente aplicar el test U de Mann-Whitney para dos muestras independientes (Lind et al., 2012) asumiendo la hipótesis nula (las respuestas son iguales en ambos

(el interés cultural es, fundamentalmente, la razón por la que viajo; cuando viajo, el interés cultural lo comparto con otros intereses; no siempre el interés cultural es mi motivo de viaje; no viajo nunca por motivos culturales), y se seleccionó únicamente aquellas personas que se identificaban con el supuesto primero o segundo. 
grupos) para observar las concordancias. Los estadísticos han sido analizados con el programa SPSS 21 para Mac.

Con relación a la fiabilidad interna del cuestionario utilizado en ambos grupos, y atendiendo a la escala de George y Mallery (2016) para el cálculo del Alfa de Cronbach, el resultado obtenido se encuentra en el intervalo bueno $(\alpha=0,829)$. Para el caso del Delphi a la academia, y tras el cálculo del coeficiente de Wilcoxon para muestras repetidas, no se hallaron diferencias significativas entre las muestras de la $1 .^{\mathrm{a}}$ y 2 . $^{\mathrm{a}}$ ronda $(\mathrm{p}=0,184>0,05)$, por lo que se paralizó y se examinaron los datos de la $2 .^{a}$ ronda.

\section{Resultados}

Un primer análisis de los resultados, y si se relacionan los ítems que han sido consensuados hacia el acuerdo en ambos grupos, revela que veinte ítems son considerados convenientemente para evaluar la adecuación turística del recurso patrimonial (tabla 6). Además, cabe resaltar que si bien el límite porcentual mínimo en un calificador lingüístico se estableció en el $66 \%$, para que un ítem fuera interpretado inicialmente como admitido junto con los otros elementos de validación, en estos veinte la concentración de respuestas supera el $75 \%$ en el calificador de acuerdo $[4,5]$, lo que indica la pertinencia de inclusión de ese ítem en el sistema de evaluación de la adaptación al uso turístico del PCI.

Por otro lado, existe un conjunto de cinco ítems en los que el consenso se ha materializado en el desacuerdo, es decir, ninguno de los grupos intervinientes los ha valorado positivamente. En los restantes ítems, hasta conformar los treinta propuestos, se manifiesta una divergencia entre un grupo y otro (para uno sí eran adecuados, pero no para el otro).

En un análisis más detallado, dentro de la dimensión 1, servicios de apoyo, y en el indicador I1 (identificado como politica de acceso), los ítems han sido prácticamente consensuados hacia el acuerdo (cinco de seis). Disponer de un horario oficial de visitas para el turismo, la existencia de un área de atención y recepción de visitantes, informar sobre el tipo de visita que puede realizarse (libre o guiada), disponer de la normativa de uso y permanencia visible, así como hojas de reclamaciones, han sido elementos acordados como adecuados por ambos grupos. Sobre el ítem D1.I1.3, expedición de tique, se observa, no obstante, divergencia entre ellos. En este caso, mientras que para la academia disponer de un sistema de tiques es necesario para, entre otros fines, llevar un control de visitas, los visitantes expusieron durante el cuestionario que no les resultaba necesario tener que obtener un documento físico que acreditase su acceso, aunque este fuera de pago.

En el indicador I2 (servicios generales) es donde aparece la mayor variabilidad de resultados. Solo tres de los nueve ítems evaluados han sido consensuados hacia el acuerdo: los relacionados con el WC, una zona de descanso y el acceso para discapacitados (este último es el único ítem en todo el cuestionario que ha obtenido la valoración de 5 en el $100 \%$ de las respuestas y en ambos 
Tabla 6. Resultados del estudio por dimensión

\begin{tabular}{|c|c|c|c|c|c|}
\hline \multirow[b]{2}{*}{ Dimensión } & \multirow[b]{2}{*}{ Indicador } & \multirow[b]{2}{*}{$\begin{array}{l}N{ }^{\circ} \text { ítems } \\
\text { a evaluar }\end{array}$} & \multicolumn{2}{|c|}{ Consensuados } & \multirow[b]{2}{*}{ Disenso } \\
\hline & & & $\begin{array}{l}\text { Hacia el } \\
\text { acuerdo }\end{array}$ & $\begin{array}{c}\text { En el } \\
\text { desacuerdo }\end{array}$ & \\
\hline \multirow{3}{*}{$\begin{array}{l}\text { Servicios } \\
\text { de apoyo (d1) }\end{array}$} & I1 Política de acceso & 6 & 5 & 0 & 1 \\
\hline & 12 Servicios generales & 9 & 3 & 4 & 2 \\
\hline & I3 Señalética & 7 & 6 & 0 & 1 \\
\hline $\begin{array}{l}\text { Servicios de } \\
\text { mediación (d2) }\end{array}$ & 14 Interpretación & 8 & 6 & 1 & 1 \\
\hline Total & & 30 & 20 & 5 & 5 \\
\hline
\end{tabular}

Fuente: elaboración propia.

grupos). Otros elementos, tales como la cafetería, las máquinas de vending, la tienda o el parking, no han sido valorados positivamente por ninguno de los dos grupos. En líneas generales, tanto la academia como los visitantes expusieron que si el PCI se encuentra ubicado en un espacio urbano, los servicios de cafetería y vending no son necesarios, al igual que el parking (a menos que se trate de un PCI ubicado en un espacio aislado, alejado). Sobre la tienda (D1. I2.7), los valores obtenidos se encuentran muy dispersos a lo largo de la escala, lo que indica una gran diversidad de opiniones sobre su inclusión. Valga la pena indicar que para la academia solo el $40 \%$ señaló este ítem como adecuado, mientras que en los visitantes no se alcanzó el 32\%.

Finalmente, y de forma curiosa, se observa disenso en los ítems wifi y consigna. El primero (D1.I2.2) es valorado como adecuado por la academia (expresó en sus resultados que el acceso gratuito a Internet puede favorecer la descarga de apps, la consulta de información sobre el PCI u otro tipo de servicios, sobre todo para quienes no dispongan de datos en roaming). Sin embargo, los visitantes no mostraron en su conjunto un acuerdo respecto a su necesidad.

Sobre la consigna (D1.I2.6), los resultados son justo al contrario: mientras que para los visitantes disponer de un espacio donde dejar parte de sus posesiones resulta pertinente para realizar una visita más cómoda, la academia no lo consideró de igual modo.

En el indicador señalética (D1.I3), también casi la totalidad de los ítems han sido consensuados hacia el acuerdo (seis de siete), tanto los relacionados con los elementos externos al PCI (soportes exteriores con información horaria, de precios e indentificativo y señalización direccional en las calles del municipio) como los internos (plano del PCI en la entrada con la distribución de salas y señalización del recorrido).

Únicamente el ítem D1.I3.4, que evaluaba el uso de los códigos QR en el exterior para acceder a la información sobre el recurso turístico, ha sido evaluado de modo diferente entre la academia y los visitantes. Mientras que los primeros sí consideran adecuado su uso, los visitantes muestran una gran dispersión en sus respuestas, con resultados similares para el calificador lingüístico de acuerdo e indeciso. 
Tabla 7. Resultados del estudio por ítem

\begin{tabular}{|c|c|c|c|}
\hline D & I & Código & Ítem \\
\hline \multirow{22}{*}{$\begin{array}{l}\text { Servicios de } \\
\text { apoyo (d1) }\end{array}$} & \multirow{6}{*}{$\begin{array}{l}\text { Política acceso } \\
\text { (i1) }\end{array}$} & d1.I1.1 & Horario oficial de visitas \\
\hline & & D1.I1.2 & Área de recepción \\
\hline & & D1.I1.3 & Expedición de tique \\
\hline & & D1.I1.4 & Visita (libre o guiada) \\
\hline & & D1.I1.5 & Normativa de uso y permanencia visible \\
\hline & & D1.I1.6 & Hojas de reclamación disponibles \\
\hline & \multirow{9}{*}{$\begin{array}{l}\text { Servicios generales } \\
\text { (i2) }\end{array}$} & d1.l2.1 & WC \\
\hline & & D1.12.2 & Wifi \\
\hline & & D1.12.3 & Zona de descanso \\
\hline & & D1.12.4 & Cafetería \\
\hline & & D1.12.5 & Vending (máquinas expendedoras de comida y bebida) \\
\hline & & D1.I2.6 & Consigna \\
\hline & & D1.12.7 & Tienda \\
\hline & & D1.I2.8 & Parking (propio o concertado) \\
\hline & & D1.12.9 & Acceso a discapacitados \\
\hline & \multirow{7}{*}{$\begin{array}{l}\text { Señalética } \\
\text { (i3) }\end{array}$} & d1.I3.1 & Soporte exterior identificativo \\
\hline & & D1.I3.2 & Soporte exterior con horarios de visita \\
\hline & & D1.13.3 & Soporte exterior con precios \\
\hline & & D1.13.4 & Código QR en el exterior para acceder a la información \\
\hline & & D1.I3.5 & El PCI está indicado en las vías de acceso más importantes del municipio \\
\hline & & D1.13.6 & Plano del PCl a la entrada con la distribución de las salas y el recorrido \\
\hline & & D1.13.7 & Recorrido interior señalizado \\
\hline \multirow{8}{*}{$\begin{array}{l}\text { Servicios } \\
\text { de mediación } \\
\text { (d2) }\end{array}$} & \multirow{8}{*}{$\begin{array}{l}\text { Interpretación } \\
\text { (i4) }\end{array}$} & D2.14.1 & Folleto específico o compartido \\
\hline & & D2.14.2 & Panel interpretativo en el exterior \\
\hline & & D2.14.3 & Paneles explicativos a lo largo del recorrido de la vista \\
\hline & & D2.14.4 & Audiovisual \\
\hline & & D2.14.5 & Servicios de audioguía \\
\hline & & D2.14.6 & Servicio de guía profesional \\
\hline & & D2.14.7 & App móvil del PCl \\
\hline & & D2.14.8 & Centros de interpretación para pinturas rupestres y yacimientos arqueológicos \\
\hline
\end{tabular}

A (academia), V (visitantes), Re (resultados), 1 (consenso atendiendo a CL, mediana y RIC), 2 (consenso por prueba U de Mann-Whitney), Ca (consenso hacia el acuerdo), Cd (consenso en el desacuerdo), D (disenso), A (aceptar hipótesis nula), R (rechazar hipótesis nula)

Fuente: elaboración propia.

En último lugar, sobre los servicios de mediación, el indicador D4 (interpretación) presenta los resultados siguientes: los folletos, paneles interpretativos interiores y exteriores, los servicios de guía y audioguía y los centros de interpretación son aspectos considerados adecuados para identificar la adaptación al uso turístico de los recursos culturales. Sin embargo, los audiovisuales no han sido incluidos en estos resultados. Por parte de la academia, porque no tiene 
Tabla 7. Resultados del estudio por ítem

calificadores lingüísticos (CL)

\begin{tabular}{|c|c|c|c|c|c|c|c|c|c|c|c|c|c|}
\hline \multicolumn{2}{|c|}{ En desacuerdo $[1,2]$} & \multicolumn{2}{|c|}{ Indeciso [3] } & \multicolumn{2}{|c|}{ De acuerdo $[4,5]$} & \multicolumn{2}{|c|}{ Mediana } & \multicolumn{2}{|c|}{ RIC } & \multirow{2}{*}{$\begin{array}{c}\text { M-W } \\
(\alpha<0,05)\end{array}$} & \multirow[b]{2}{*}{ V } & \multicolumn{2}{|c|}{$\operatorname{Re}$} \\
\hline A & v & A & v & A & v & A & $\mathrm{v}$ & A & v & & & 1 & 2 \\
\hline 0,00 & 0,06 & 0,04 & 0,05 & 0,96 & 0,89 & 5 & 4 & 0 & 1 & 0,272 & & $\mathrm{Ca}$ & A \\
\hline 0,00 & 0,02 & 0,12 & 0,03 & 0,88 & 0,95 & 5 & 5 & 1 & 1 & 0,097 & & $\mathrm{Ca}$ & A \\
\hline 0,04 & 0,11 & 0,12 & 0,31 & 0,84 & 0,57 & 5 & 4 & 1 & 2 & 0,014 & & $\mathrm{D}$ & $\mathrm{R}$ \\
\hline 0,04 & 0,01 & 0,04 & 0,06 & 0,92 & 0,93 & 5 & 5 & 0 & 1 & 0,596 & & $\mathrm{Ca}$ & A \\
\hline 0,04 & 0,01 & 0,04 & 0,04 & 0,92 & 0,96 & 5 & 5 & 1 & 1 & 0,994 & & $\mathrm{Ca}$ & A \\
\hline 0,00 & 0,04 & 0,12 & 0,06 & 0,88 & 0,90 & 5 & 5 & 0 & 1 & 0,719 & & $\mathrm{Ca}$ & A \\
\hline 0,00 & 0,02 & 0,00 & 0,02 & 1,00 & 0,97 & 5 & 5 & 0 & 0 & 0,363 & & $\mathrm{Ca}$ & A \\
\hline 0,04 & 0,16 & 0,16 & 0,26 & 0,80 & 0,58 & 5 & 4 & 1 & 2 & 0,034 & & $\mathrm{D}$ & $\mathrm{R}$ \\
\hline 0,00 & 0,03 & 0,00 & 0,08 & 1,00 & 0,89 & 5 & 5 & 0 & 1 & 0,082 & & $\mathrm{Ca}$ & A \\
\hline 0,08 & 0,26 & 0,20 & 0,35 & 0,72 & 0,39 & 4 & 3 & 2 & 2 & 0,002 & & $\mathrm{Cd}$ & $\mathrm{R}$ \\
\hline 0,20 & 0,41 & 0,16 & 0,29 & 0,64 & 0,30 & 4 & 3 & 2 & 2 & 0,003 & & $\mathrm{Cd}$ & $\mathrm{R}$ \\
\hline 0,12 & 0,10 & 0,16 & 0,23 & 0,72 & 0,67 & 5 & 4 & 2 & 1 & 0,828 & & $\mathrm{D}$ & $A^{*}$ \\
\hline 0,12 & 0,29 & 0,48 & 0,40 & 0,40 & 0,32 & 3 & 3 & 1 & 2 & 0,190 & & $\mathrm{Cd}$ & $A^{*}$ \\
\hline 0,12 & 0,23 & 0,16 & 0,30 & 0,72 & 0,47 & 5 & 3 & 2 & 1 & 0,031 & & $\mathrm{Cd}$ & $\mathrm{R}$ \\
\hline 0,00 & 0,00 & 0,00 & 0,00 & 1,00 & 1,00 & 5 & 5 & 0 & 0 & 0,804 & & $\mathrm{Ca}$ & A \\
\hline 0,00 & 0,01 & 0,08 & 0,02 & 0,92 & 0,97 & 5 & 5 & 0 & 0 & 0,176 & & $\mathrm{Ca}$ & A \\
\hline 0,00 & 0,01 & 0,08 & 0,01 & 0,92 & 0,98 & 5 & 5 & 0 & 0 & 0,160 & & $\mathrm{Ca}$ & A \\
\hline 0,00 & 0,02 & 0,08 & 0,04 & 0,92 & 0,94 & 5 & 5 & 0 & 0 & 0,654 & & $\mathrm{Ca}$ & A \\
\hline 0,00 & 0,14 & 0,16 & 0,39 & 0,84 & 0,47 & 5 & 3 & 1 & 1 & 0,000 & & $\mathrm{D}$ & $\mathrm{R}$ \\
\hline 0,00 & 0,01 & 0,04 & 0,03 & 0,96 & 0,96 & 5 & 5 & 1 & 0 & 0,950 & & $\mathrm{Ca}$ & A \\
\hline 0,00 & 0,00 & 0,00 & 0,03 & 1,00 & 0,97 & 5 & 5 & 1 & 1 & 0,427 & & $\mathrm{Ca}$ & A \\
\hline 0,04 & 0,07 & 0,04 & 0,13 & 0,92 & 0,80 & 5 & 4 & 1 & 1 & 0,179 & & $\mathrm{Ca}$ & A \\
\hline 0,00 & 0,02 & 0,04 & 0,04 & 0,96 & 0,93 & 5 & 5 & 0 & 1 & 0,616 & & $\mathrm{Ca}$ & A \\
\hline 0,00 & 0,07 & 0,12 & 0,12 & 0,88 & 0,81 & 5 & 4 & 1 & 1 & 0,386 & & $\mathrm{Ca}$ & A \\
\hline 0,00 & 0,01 & 0,00 & 0,03 & 1,00 & 0,96 & 5 & 5 & 1 & 0 & 0,345 & & $\mathrm{Ca}$ & A \\
\hline 0,00 & 0,05 & 0,56 & 0,22 & 0,44 & 0,73 & 3 & 4 & 1 & 2 & 0,004 & & $\mathrm{Cd}$ & $\mathrm{R}$ \\
\hline 0,00 & 0,02 & 0,24 & 0,18 & 0,76 & 0,80 & 4 & 4 & 1 & 1 & 0,624 & & $\mathrm{Ca}$ & A \\
\hline 0,00 & 0,02 & 0,24 & 0,15 & 0,76 & 0,83 & 4 & 4 & 1 & 1 & 0,363 & & $\mathrm{Ca}$ & A \\
\hline 0,08 & 0,13 & 0,20 & 0,35 & 0,72 & 0,52 & 4 & 4 & 1 & 1 & 0,040 & & $\mathrm{D}$ & $\mathrm{R}$ \\
\hline 0,08 & 0,04 & 0,08 & 0,12 & 0,84 & 0,84 & 5 & 4 & 1 & 1 & 0,855 & & $\mathrm{Ca}$ & A \\
\hline
\end{tabular}

clara su función (obsérvese que más del 50\% de las respuestas se encuentran en el calificador indeciso) y, según los visitantes, porque su contenido es en muchas ocasiones poco atractivo (si bien se concentran las respuestas en de acuerdo, el RIC obtiene un valor de 2, lo que indica una variabilidad en las respuestas que hace inadecuada su inclusión). Llama la atención el ítem D2.I4.7, sobre una app móvil del recurso cultural, y el disenso obtenido: mientras que la academia 
lo considera pertinente en un 72\%, solo algo más del 50\% de los visitantes lo estima adecuado.

Finalmente, estos resultados son coincidentes en más de un $90 \%$ con los obtenidos en la prueba U de Mann-Whitney (28 de los 30 ítems). Solo en la consigna (D1.I2.6) y la tienda (D1.I2.7) es donde se observa una diferencia según la técnica empleada. La explicación es que los resultados se encuentran dispersos en la escala de manera muy homogénea entre los grupos, de ahí que la técnica (que analiza la variabilidad entre dos muestras) los considere similares, pero son rechazados porque no cumplen con los criterios de la metodología de este estudio.

\section{Conclusiones}

Si se asume que el patrimonio cultural es una construcción sociocultural dependiente de los valores, intereses, tradiciones e identidades de cada sociedad (el nosotros del nosotros) y, por ello, condicionado subjetivamente (no tanto por su valor intrínseco como por lo que representa), los recursos turísticos construidos a partir de este patrimonio heredarán tales características, además de las propias resignificaciones que adquirirá para su consumo turístico (el nosotros de los otros).

Bajo este argumento, podría parecer que su atractivo es un elemento suficiente para convertirse en recurso turístico (UIOOT, 1971). Ahora bien, puesto que ningún patrimonio ha nacido con esa finalidad de ocio, su acondicionamiento para esa nueva función resulta una tarea indiscutible (OMT, 1999). Se deja así constancia de que la adaptación del patrimonio cultural al uso turístico es una tarea necesaria cuando se desea que aquel sea convertido a esta nueva función.

Si bien existen propuestas en la literatura académica revisada en relación con esa transformación humana necesaria, las aportaciones no exponen en detalle qué tipo de elementos son los que constituirían esa adecuación del patrimonio cultural para el uso turístico. Por esta razón, y a diferencia de los sistemas de evaluación de los recursos que tienen por objeto identificar su grado de atractivo para la actividad turística, esta propuesta expone qué elementos son necesarios para determinar que un PCI está adaptado al uso turístico. Y puesto que se ha manifestado el carácter subjetivo asociado a la idea de patrimonio y recurso turístico, resulta pertinente integrar las percepciones tanto de quienes lo disfrutan como de quienes lo estudian.

Estructurada la base del estudio sobre los trabajos de Velasco (2009) y Mateos (2012), entre otros, se concluye que de los 30 ítems presentados y valorados por los dos grupos participantes, 20 de ellos han alcanzado el consenso hacia el acuerdo de forma unánime. Fundamentalmente, son los relacionados con los indicadores de política de acceso y señalética.

El primer indicador se presenta como un aspecto básico, relacionado con la disponibilidad de acceso al PCI en condiciones que garanticen la experiencia turística. Se destaca la importancia de establecer un horario específico para 
las visitas, más si ese PCI comparte este nuevo uso turístico con otro anterior y principal, de modo que se asegure una adecuada convivencia entre usuarios y finalidades. Esta cuestión fue comentada por ambos grupos, en especial por los visitantes, quienes expresaban su descontento en experiencias anteriores en las que era imposible acceder al PCI (porque estaba cerrado) o solo en horarios no adaptados (en horario de misa, en horario de atención al ciudadano, en horario según la festividad, en horario de actividades culturales concretas). La atención al visitante también se presenta como un ítem destacado. Sin embargo, algunos comentarios recogidos durante el Delphi y las encuestas manifiestan que, en aquellos casos donde el PCI se ubica en un espacio rural (lo que en muchas ocasiones hace inviable disponer de inversión para adecuar cada espacio con material y personal), resulta indispensable, al menos, la existencia de un punto de atención al visitante en el municipio o en el nodo turístico a visitar.

En el indicador señalética, que ayuda al visitante a ubicar e identificar el PCI, los ítems propuestos concentran más del $80 \%$ de las valoraciones en el acuerdo, a excepción de los códigos QR. Aún hoy en día, y aunque la tecnología facilita en todo momento la información sobre dónde uno se encuentra, el visitante continúa valorando positivamente la existencia de información exterior básica sobre el recurso a visitar.

Sobre los servicios generales, aquellos que no son estrictamente de carácter turístico, resulta paradójica la valoración de la academia frente a la de los visitantes con relación a algunos servicios. Por lo general, la academia valoró muy por encima ítems dirigidos a la mejora de la estancia de los visitantes, como la cafetería, las máquinas de vending y el parking. Este hecho pone de manifiesto la importancia de la participación de ambos grupos para contrastar las propuestas que pueden parecer adecuadas pero que en realidad son secundarias para el grupo de interés (en este caso los visitantes).

De hecho, sirvan como ejemplo los ítems de carácter tecnológico (app móvil, uso de códigos QR y wifi), que la academia considera pertinentes que estén presentes en el proceso de adecuación a recurso turístico. Sin embargo, quienes supuestamente se beneficiarán de tales servicios no llegan a un acuerdo sobre su necesaria idoneidad.

Este hecho indica claramente que la selección de un único grupo daría como resultado un mayor consenso respecto a los ítems a incluir. Sin embargo, si se hubiera tomado esa decisión (seleccionar un único grupo para esta investigación), la visión obtenida del análisis debería haber quedado circunscrita a ese target, pues uno solo no debería representar al total de actores por constituir un sesgo más que considerable y una propuesta de evaluación más arriesgada.

Además, otro hecho queda patente tras la visualización de los resultados obtenidos según las técnicas implementadas y los grupos participantes: existen entre ambos actores algunas concepciones de partida distintas sobre la adaptación (obsérvese que, de los cuatro ítems en disenso, en tres la academia está de acuerdo y solo en uno los visitantes). Sirva como ejemplo que la academia no considera necesarios ni los audiovisuales ni las consignas, cuando todo visitante indicó que eran elementos adecuados. 
A tenor de los resultados, se observa que los grupos poseen para ciertos ítems visiones particulares, a veces alineadas y otras contrapuestas, condicionadas, cómo no, por la realidad de cada papel. Adaptar el PCI al uso turístico implica necesariamente contemplar un conjunto de elementos, tanto físicos como inmateriales, que determinarán finalmente las posibilidades turísticas del bien, sin que sea, como se ha venido haciendo hasta el momento, una cuestión de capacidad natural de atractivo ni de la percepción particular que pueda tener un grupo determinado.

Porque si se acepta que el PCI no nace con una finalidad turística y que sus posibilidades para este uso están condicionadas por la mirada turística (Urry, 2004), es irrenunciable apostar por una evaluación más integrada en la planificación de los recursos para el turismo que incluya métodos más científicos, pero sobre todo más participativos por parte de los actores a quien afecta y que se ven afectados por ese patrimonio si de verdad se desea conservar el bien y atender las necesidades de todos ellos.

Además, también hay que advertir que esta propuesta para adaptar el PCI al uso turístico, escenificada en los 20 ítems acordados, queda condicionada al tipo de recurso cultural y al momento en que se realizó la evaluación, pues una vez más se insiste en que no se trata de un sistema de homogeneización de los PCI para el turismo, ya que este es una actividad dinámica y cambiante, que depende del entorno social, político, económico y tecnológico de cada momento, sino de un punto de partida condicionado por tales circunstancias.

Los resultados obtenidos deberán servir como un modelo inicial con el que evaluar en qué medida el PCI está adaptado para un uso turístico. En realidad, es la otra cara de la moneda, que, junto con el atractivo, conformará un paso decisivo hacia una teoría del uso turístico.

\section{Referencias bibliográficas}

Almirón, Analía; Bertoncello, Rodolfo y Troncoso, Claudia Alejandra (2006). «Turismo, patrimonio y territorio. Una discusión de sus relaciones a partir de casos de Argentina». Estudios y Perspectivas en Turismo, 15 (2), 101-120. $<$ https://doi.org/10.25145/j.pasos.2012.10.007>

Anton, Salvador (2000). «Turismo, territorio y cultura». Actas de Turismo y Ciudad: IV Coloquio de Geografia Urbana y VI Coloquio de Geografia del Turismo, Ocio y Recreación, 29-41. Las Palmas de Gran Canaria.

Anton, Salvador; Fernández, Alfonso y González, Francesc (2007). «Los lugares turísticos». En: Anton, Salvador; GonzÁlez, F. y Cors Iglesias, Martí (eds.). A propósito del turismo: la construcción social del espacio turístico, 103-206. Barcelona: UOC.

ArgYrous, George (2011). Statistics for research: With a guide to SPSS. Los Angeles: SAGE.

Ariño, Antonio (2002). La expansión del patrimonio cultural. Revista de Occidente, 250, 129-150.

Arnandis-i-Agramunt, Ruben (2017). La adaptación al uso turístico de los recursos culturales. Una propuesta de evaluación para una comprensión más equilibrada de 
la actividad turística. Valencia: Universitat de València. Recuperado de <http:// roderic.uv.es/handle/10550/59172>.

- (2018). "Una revisión a la planificación de los recursos: Sobre los enfoques de evaluación y los modelos de adaptación al uso turístico». Investigaciones Turisticas, $15,168-197$. <https://doi.org/10.14198/INTURI2018.15.08>

Ávila, Reyes (2008). «Metodología básica para la evaluación ponderada de los recursos patrimoniales en su proceso hacia la conversión en productos turísticos». En: Universidad de Sevilla (ed.). Turismo rural y desarrollo local, 229-238. Sevilla: Universidad de Sevilla, Secretariado de Publicaciones.

Ballantyne, Roy; Hughes, Karen y Bond, Nigel (2016). «Using a Delphi approach to identify managers' preferences for visitor interpretation at Canterbury cathedral world heritage site». Tourism Management, 54, 72-80. <http://dx.doi.org/10.1016/j.tourman.2015.10.014>

Ballart, Josep y Juan i Tresserras, Jordi (2001). Gestión del patrimonio cultural. Barcelona: Editorial Ariel.

Bonfill, Guillermo (1993). «Nuestro patrimonio cultural: Un laberinto de significados». En: Florescano, Enrique (ed.). El patrimonio cultural de México, 19-40.

Bourdieu, Pierre (1998). La distinción. Criterio y bases sociales del gusto. Madrid: Taurus.

Calle, Manuel de la (2002). La ciudad histórica como destino turístico. Barcelona: Ariel.

Coll-Serrano, Vicente; Blasco-Blasco, Olga; Carrasco-Arroyo, Salvador y Vila-Lladosa, Luis (2013). "Un sistema de indicadores para el seguimiento y evaluación de la gestión sostenible del patrimonio cultural». Transinformaçao, 25 (1), 55-63.

<http://dx.doi.org/10.1590/S0103-37862013000100006>

Contr, Alfredo y Cravero, Santiago (2010). «Patrimonio, comunidad local y turismo: La necesidad de planificación para el desarrollo sostenible». Notas en Turismo y Economía, 1, 8-31.

CoRTÉs, Trinidad (2002). Recuperación de patrimonio cultural urbano como recurso turístico. Madrid: Universidad Complutense de Madrid, Servicio de Publicaciones.

Dalkey, Norman; Brown, Brian y Cochran, Samuel (1969). "The Delphy methods III: use of self rating to improve groups estimates». The Rand Corporation (ed.).

Donohoe, Holly y Needham, Roger (2009). «Moving best practice forward: Delphi characteristics, advantages, potential problems, and solutions». International Journal of Tourism Research, 11 (5), 415-437. <https://doi.org/10.1002/jtr.709>

FERnÁndez, Víctor (2003). «Patrimonio y desarrollo. ¿¿Realidad o deseo?» En: Jornadas de Patrimonio y Desarrollo, 29-61. Úbeda-Baeza: Asociación de Geógrafos Españoles y Consejería de Cultura de la Junta de Andalucía.

Flores, David (2010). «Factores de desarrollo turístico actual y futuro de los parques naturales andaluces de montaña». Revista de Estudios Regionales, 87, 157-185.

Fundación Turismo Valencia. <www.turisvalencia.es> [Consulta: 14 de febrero de 2018].

George, Darren y Mallery, Paul (2016). IBM SPSS statistics 23 step by step: A simple guide and reference (14 ed.). Nueva York: Routledge.

Graham, Brian; Ashworth, Greg y Tunbridge, John (2000). A geography of heritage: Power, culture, and economy. Nueva York: Oxford University Press. 
Gunn, Clare (1972). Tourism planning: Basics, concepts, cases (1 ed.). Londres: Taylor \& Francis.

- (1997). Vacationscape: Developing tourist areas (3 ed.). Londres: Taylor \& Francis.

Habibi, Arash; Sarafrazi, Azam y Izadyar, Sedigheh (2014). «Delphi technique theoretical framework in qualitative research». The International Journal of Engineering and Sciences, 3 (4), 8-13.

Hernàndez i Martí, Gil-Manuel; Santamarina, Beatriz; Moncusí, Albert y Albert, Maria (2005). La memoria construida: Patrimonio cultural y modernidad. Valencia: Tirant lo Blanch.

Icomos (1966). International charter for the conservation and restoration of monuments and sites. Decisions and resolutions. París: Icomos.

Icomos \& UnwTo (1993). Cultural tourism. Tourism at world heritage cultural sites: The site manager's handbook. Sri Lanka: Publications Committee.

Johnson, David y KIng, Malcom (1988). Basic forecasting techniques. Londres: Butterworths.

Kaplan, A.; Skogstad, A. y Girshik, M. (1950). "The prediction of social technological events». Public Opinion Quartery, 14 (1), 93-110. <https://doi.org/10.1086/266153>

KaYnaK, Erdener y Macaulay, James (1984). «The Delphi technique in the measurement of tourism market potential». Tourism Management, 5 (2), 87-101. <http://dx.doi.org/10.1016/0261-5177(84)90056-6>

Konu, Henna (2015). «Developing nature-based tourism products with customers by utilising the Delphi method». Tourism Management Perspectives, 14, $42-54$. <http://dx.doi.org/10.1016/j.tmp.2015.03.003>

Landeta, Jon (2002). El método Delphi: Una técnica de previsión del futuro (1a ed.). Barcelona: Ariel.

- (2006). "Current validity of the Delphi method in social sciences». Technological Forecasting and Social Change, 73 (5), 467-482. <http://dx.doi.org/10.1016/j.techfore.2005.09.002>

Landeta, Jon; Barrutia, Jon y Lertxundi, Aitziber (2011). «Hybrid Delphi: A methodology to facilitate contribution from experts in professional contexts». TFS Technological Forecasting \& Social Change, 78 (9), 1.629-1.641. <https://doi.org/10.1016/j.techfore.2011.03.009>

Leask, Anna y Fyall, Alan (2006). Managing world heritage sites. Oxford, Burlington, Mass.: Butterworth-Heinemann.

LeE, Cheng-Fei y KIng, Brian (2008). «Using the Delphi method to assess the potential of Taiwan's hot springs tourism sector». JTR International Journal of Tourism Research, 10 (4), 341-352.

LeIPER, Neil (1990). "Tourist attraction systems». Annals of Tourism Research, 17 (3), 367-384. <https://doi.org/10.1016/0160-7383(90)90004-B>

LEw, Alan (1987). "A framework of tourist attraction research». Annals of Tourism Research, 14 (4), 553-575. <https://doi.org/10.1016/0160-7383(87)90071-5>

Lima, Silvio; Nóbreg, Wilker; Bahi, Mirleide y Pian, Auda (2012). «Planificación y gestión de las visitas al patrimonio natural y cultural y a los atractivos turísticos». Estudios y Perspectivas en Turismo, 21 (2), 355-371.

Lind, Douglas; Marchal, William y Wathen, Samuel (2012). Estadística aplicada a los negocios y a la economía (15a ed.). México: McGraw-Hill. 
Linstone, Harold y Turoff, Murray (2002). The Delphi method: Techniques and applications. Addison-Wesley Pub.

MacCannell, Dean (1976). The tourist: a new theory of the leisure class. Nueva York: Schocken Books.

Marchena, Manuel y Repiso, Fernando (1999). «Turismo cultural. El caso de Sevilla». Cuadernos de Turismo, 4, 33-50.

Marcos, Javier (2004). "La tradición, el patrimonio y la identidad». Revista de Estudios Extremeños, 60 (3), 925-956.

Mateos, Santos (2012). "Difusión cultural. La magdalena de los productos patrimoniales». E-Rph, 10, 3-21.

Middleton, Víctor (1994). «Vision, strategy and corporate planning: An overview». En: Harrison, Richard (ed.). Manual of heritage management, 3-11. Butterworth-Heinemann.

Moncusí, Albert (2005). «La activación patrimonial y la identidad» En: Hernàndez i Martí, Gil-Manuel; Santamarina, Beatriz; Moncusí, Albert y Albert, Maria (eds.). La memoria construida: Patrimonio cultural y modernidad, 91-121. Valencia: Tirant lo Blanch.

Monteserin, Obdulia (2008). Turismo y desarrollo territorial: Los planes de dinamización turística en la interpretación y puesta en valor del territorio. Universidad Complutense de Madrid: Tesis.

Murphy, M.; Black, N.; Lamping, D.; McKee, C.; Sanderson, C. y Askham, J. (1998). Consensus development methods, and their use in clinical guideline development, 2 (3). Health Technol Assessment.

Organización Mundial del Turismo (1999). Guía para administraciones locales: Desarrollo turístico sostenible. Madrid: Organización Mundial del Turismo.

Pearce, Phillip (1991). "Analyzing tourist attractions». Journal of Tourism Studies, 1 (1), 46-55.

- (1998). "Marketing and management trends in tourist attractions». Asia Pacific Journal of Tourism Research, 3 (1), 1-8. <https://doi.org/10.1080/10941669908722002>

Pedro-Botet, Juan; Barrios, Vivencio; Pascual, Vicente; Ascaso, Juan; Cases, Aleix; Millán, Jesús; Serrano, Adalberto y Pintó, Xavier (2016). «Consenso Delphi sobre el manejo de la dislipidemia en pacientes con alteración del metabolismo de la glucosa: Estudio Diana». ARTERI Clinica e Investigación en Arteriosclerosis, 28 (3), 132-140. <https://doi.org/10.1016/j.arteri.2015.12.003>

Plaza, Vicente; Calle, Myriam; Molina, Jesús; Quirce, Santiago; Sanchis, Joaquín; Viejo, José y Caballero, Fernando (2012). «Validación externa de las recomendaciones del consenso multidisciplinar sobre terapia inhalada». Archivos de Bronconeumología, 48 (6), 189-196.

<http://dx.doi.org/10.1016/j.arbres.2012.01.001>

Prats, Llorenç (1997). Antropología y patrimonio. Barcelona: Ariel.

- (1998). «El concepto de patrimonio cultural». Política y Sociedad, 27, 63-76.

Pinassi, Carlos (2012). "Turismo cultural en el centro histórico de Bahía Blanca (Argentina). Análisis y propuestas para su desarrollo turístico-recreativo». Turismo y Sociedad, XIII, 145-169.

Pulido, Juan Ignacio (2007). «El turismo en el desarrollo de los parques naturales andaluces: Un análisis Delphi de los principales déficit». Revista de Estudios Empresariales, 1, 110-137. 
Pulido, Juan Ignacio y SÁnchez, Marcelino (2009). «Measuring tourism sustainability: Proposal for a composite index». Tourism Economics Tourism Economics, 15 (2), 277-296. <https://doi.org/10.5367/000000009788254377>

Richardson, John (1996). Marketing Australian travel \& tourism: Principles and practice. Elsterwick, Victoria: Hospitality Press.

Ritzer, George (1996). La McDonalización de la sociedad. Un análisis de la racionalización en la vida cotidiana. Barcelona: Ariel.

Rowe, Gene y Wright, George (2011). «The Delphi technique: Past, present, and future prospects - Introduction to the special issue». Technological Forecasting \& Social Change, 78 (9), 1.487-1.490. <https://doi.org/10.1016/j.techfore.2011.09.002>

Silva, Rocío y Fernández, Víctor (2008). «El patrimonio y el territorio como activos para el desarrollo desde la perspectiva del ocio y del turismo». Investigaciones Geográficas, 46, 69-88. <https://doi.org/10.14198/INGEO2008.46.04>

Solsona, Javier (2010). Desarrollo turístico en espacio rural, análisis de la situación y prospectiva. Estudio aplicado a la Comunitat Valenciana. Universitat Jaume I: Tesis.

Stevens, Tailor (1991). "Visitor attractions: Their management and contribution to tourism». En: Cooper, Christopher (ed.). Progress in tourism, recreation and hospitality management, 3, 106-113. Londres: Belhaven.

Swarbrooke, John (2002). The development and management of visitor attractions (2 ed.). Oxford: Butterworth-Heinemann.

Toselli, Claudia (2006). «Algunas reflexiones sobre el turismo cultural». Pasos. Revista de Turismo y Patrimonio Cultural, 4 (2), 175-182. <https://doi.org/10.25145/j.pasos.2006.04.012>

Tsaur, Sheng-Hshiung; Lin, Yu y Lin, Jo-Hui (2006). «Evaluating ecotourism sustainability from the integrated perspective of resource, community and tourism». Tourism Management, 27 (4), 640-653. <https://doi.org/10.1016/j.tourman.2005.02.006>

Turoff, Murray (1971). "Delphi and its potential impact on information systems». Conference Procedings, 39, 317-326. <https://doi.org/10.1145/1479064.1479122>

Unesco (2014). Managing cultural world heritage. París: Unesco.

Unión Internacional de Organismos Oficiales de Turismo (1971). Estudio sobre la oferta potencial internacional de los recursos turísticos. Ginebra: Unión Internacional de Organismos Oficiales de Turismo.

URRY, John (2004). La mirada del turista. Lima: Universidad de San Martín de Porres.

Valle, Ana Lía del y Soledad, Silvana (2015). «Aporte teórico conceptual al turismo como disciplina académica a partir de la patrimonialización como proceso de valorización turística de los territorios» Pasos. Revista de Turismo y Patrimonio Cultural, 13 (1), 145-156. <https://doi.org/10.25145/j.pasos.2015.13.010>

Velasco, María (2009). "Gestión turística del patrimonio cultural: Enfoques para un desarrollo sostenible del turismo cultural». Cuadernos de Turismo, 23, 237-253.

Walsh-Heron, John (1990). The management of visitor attractions and events. Englewood Cliffs (Nueva Jersey): Prentice Hall. 
WeAver, David Bruce y Lawton, Laura (2007). "Just because it's gone doesn't mean it isn't there anymore: Planning for attraction residuality». Tourism Management, 28 (1), 108-117. <https://doi.org/10.1016/j.tourman.2006.01.002>

WeIDENFELD, Adi y LeAsK, Anna (2013). «Exploring the relationship between visitor attractions and events: Definitions and management factors». Current Issues in Tourism, 16 (6). <https://doi.org/10.1080/13683500.2012.702736>

World TOURISM Organization (1979). Evaluating tourism resources - Evaluación de los recursos turísticos (versión española). Madrid: UNWTO. 
